\title{
Becoming an L2 learner (again): How a brief language learning experience sparked connections with SLA theory
}

\begin{abstract}
A brief 'language learning experience' (LLE) in Thai was integrated into a Second Language Development course as part of postgraduate TESOL study at an Australian university. Sixty primary and secondary teachers from a range of schools evaluated the impact of the LLE by means of a questionnaire; and proved highly affirming of its value, nominating awareness of experiential learning and affective factors as the most salient outcomes. An additional and unexpected outcome was its impact upon the lecturer himself, who also served as the language instructor. This dual role of lecturerinstructor resulted in the creation of a different tenor of relationships with teachers; in the lecturer's deeper understanding of the constraints of teaching a language other than one's own; and most directly, in his enhanced capacity to present key concepts in the field of Second Language Development.
\end{abstract}

\section{Keywords}

Language learning experience (LLE), language teacher education, teacher-educator development, SLA

\section{Background}

This practitioner research project focuses on ESL teachers and their lecturer who are working in an English-dominant context with students of various language backgrounds; a context where the teacher is usually monolingual, or 'is expected to behave as if s/he is' (E. Ellis, 2004, p. 56). In these respects, the monolingual majority of ESL teachers is quite different from both the majority of EFL teachers, and, for that matter, from foreign language teachers, most of whom are bilingual, and whose classrooms can draw upon both native as well as target languages (Bigelow \& Tedick, 2005). For teachers who are monolingual in English, there is a crucial challenge to be faced: how we can disassociate from our mother-tongue, and re-approach it from a learner perspective? It seems that the learning of another language oneself could be a catalytic experience for ESL teachers; and indeed, one of R. Ellis's 'eleven principles' proposed for the design of TESOL teacher training programs is precisely this: 'teachers' reflection on their own experience of learning a new language' (2010, p. 96).

The project explores one possible means for such a process to take place: what has been known in the literature as the Language Learning Experience (LLE). Designed to educate language teachers rather than to develop L2 proficiency, the LLE may take the shape of a 'shock lesson', or may extend across one semester of part-time study. In the present case, it was delivered in six, weekly, half-hour sessions.

The impetus for the research came from my own teaching at a major metropolitan university in Australia. One subject in the postgraduate TESOL program is that of Second Language Development (SLD), more often known internationally as Second Language Acquisition (SLA), which was taught here in four modules: L1 and L2; The Learning Environment; The Learner; and Bilingualism. This subject had been negatively evaluated as offering relatively little to classroom practice, and as being rather inaccessible in its research literature. Similar teacher responses to coursework in SLA have been reported in the US (for example van Lier, 2004, p. 80) and in the UK (MacDonald, Badger, \& White, 2001); and the SLA-Language Pedagogy nexus itself has been discussed in depth by R. Ellis (2010). From my own perspective as lecturer in this and in other TESOL subjects, I had additional concerns about the sometimes Anglocentric and Eurocentric nature of teachers' responses to a variety of 'other' languages and cultures. Although linguistic and cultural diversity is core to the TESOL profession, around $90 \%$ of the local ESL teachers who attended our programs were monolingual, having either learned no foreign language, or having only studied some French or German at high school.

For these reasons, then, I introduced a short LLE into the SLD subject, whereby all teachers were required to participate in Thai language classes over six consecutive weeks of the semester. 
The purpose of the strategy was both pedagogic and academic: for teachers to gain insights into the language learning process by reflecting upon their LLE and relating it to the SLA research literature. Nearly all other LLEs conducted to date have examined teaching methodology, sometimes with a secondary focus upon learning, particularly in its affective dimension. My project, on the other hand, explicitly directed teachers' attention away from teaching methodology and onto their own learning. I acknowledge that expecting teachers to disregard methodology may be unrealistic; but this was an 'ambit' move, to signal that methodology should not be the focus of teachers' analysis.

Typically the LLE is delivered by persons other than the subject-lecturer; however, in this project, I was also the L2 instructor. This decision was made as a result of experiments with three previous cohorts, when on each occasion, 'outside' instructors had taught either Vietnamese, Cantonese, or Auslan (Australian sign language). Unfortunately in each case, negative evaluations of teaching methodology dominated teachers' responses, even though they had been directed to focus principally on their own learning. The triple role which I thus took on, that of language instructor, subject lecturer, and researcher, was not without its challenges, particularly as I was neither a native nor expert speaker of the target language, but it did provide a unique perspective. More broadly, self-analysis of the practices of TESOL teacher educators is still rare in the literature (Bartels, 2002; Wright, 2010) - though for an interesting exception, also related to SLA, see Gorsuch and Beglar (2004). Therefore, this project seeks to make a contribution to the teacher-educator literature, as well as to that of teacher-development.

Since I wanted teachers to retain a focus on their learning, rather than on my teaching, I paid particular attention when designing lessons to factors of affect, language of instruction, content, and skills.

In terms of affect, while some forms of the LLE aim to 'shock' participants into new ways of experiencing an L2, I never sought to embarrass, worry, or confuse teachers in any way. On the contrary, my aim was to offer as supportive and non-threatening an affective environment as was possible. Indeed, running throughout the various learning experiences was a sense of fun and play, which came sometimes from teachers' efforts to understand or produce Thai, and sometimes from my efforts to communicate with the aid of mime, visuals, and vocal exaggeration.

In most previous studies, L2 has been used exclusively as the medium of instruction. And indeed, for the majority of this LLE, I decided to speak and apparently understand only L2 (Thai). However, in the last five minutes of each class, I reverted to English, taking questions, and explaining points of form, meaning or culture. It was important for the bulk of the lesson to be conducted in L2 so that teachers could experience the situation faced by their ESL students, viz not sharing a common language with their teacher. At the same time, I intended that the five-minute L1 support would demonstrate its potential value in learning an L2 (Forman 2010, 2012).

In regard to content, I sought to move from the known to the new by relying on familiar fields of geography, music, food, and other aspects of Australian and Thai cultures, including, in the last session, the plot of a Thai/Australian film 'The Good Woman of Bangkok'. I also drew upon the relatively few English words which have entered the Thai language - for example, coffee, beer, and ice cream.

Classroom activities themselves focussed primarily upon receptive L2 skills. This required both message simplification and message 'abundancy' (Gibbons, 2003) - i.e. the use of extralinguistic semiosis such as drawings and mime. Audio clips of Thai native speakers from the Linguaphone series (1995) provided practice in listening and a basis for pronunciation drills. Limited kinds of L2 speaking activities through question and answer pairwork were provided (with one Find Someone Who activity). It was not possible in this short period of time to introduce the Thai alphabet. Instead I used English transliteration of Thai, which enabled students to complete some simple L2 reading and writing tasks - usually in the form of cloze passages.

Previous research on the LLE tends to cluster in three areas: the connection of professional experience with reflection (Wallace, 1991); teacher language awareness (Wright \& Bolitho, 1997); and to a lesser extent, teacher cognitions/beliefs (Borg, 2003). A fourth concept, offered by E. Ellis (2012, p. 15), is relevant here, that of 'language learning awareness', which she defines as 'the understanding of and empathy with the challenges 
faced by learners of an additional language'. This is a notion which provides a connection across all three fields above, as it is a sub-set of language awareness, directly impacts upon cognitions/beliefs, and - critically - is said to be 'only achievable through direct experience and reflection upon that experience' (ibid; italics added). It is upon this concept that the present project seeks to build.

\section{Research Questions}

The project explored the following research questions:

(1) To what the extent was the LLE valued by teachers at a summative point in their TESOL studies?

(2) Why or why not did teachers consider the LLE to be of value?

(3) What was the instructor-lecturer's perspective, both on teachers' responses, and on his own experience of delivering the LLE?

(4) How appropriate was the duration of the program?

\section{Methodology}

\section{Participants}

A total of sixty ESL teachers comprised three successive cohorts of postgraduates enrolled at a metropolitan university in Australia. All were currently employed by the State or Catholic school systems. Eighty-eight percent of teachers were female, and $12 \%$ male. Seventy-seven percent fell into either the $31-40$ or $41-50$ age brackets ( $44 \%$ and $33 \%$ respectively); $19 \%$ were aged 21-30; and 3\% aged 51-60. The instructor-lecturer had previously taught secondary school ESL in Australia (as well as EFL in Asia), was male, and in the 41-50 age bracket.

In terms of bilinguality, $52 \%$ of teachers self-reported to have no second language; $37 \%$ reported proficiency at basic to intermediate levels; and 11\% were bilingual. (Basic proficiency here refers to minimal L2 attainment such as that gained by foreign language study at junior High School; Intermediate represents proficiency at matriculation or Year 12 level; and Bilingual, the capacity to function well, though not perfectly, in two languages across a range of registers and genres.) The lecturer-instructor was fluent in French. His command of Thai was only basic, but crucially, could demonstrate accurate pronunciation of this tonal language.

\section{Procedure and materials}

Teachers' views about the LLE were obtained in two stages. In the first stage, teachers had been required to analyse their LLE in the form of a weekly journal whose cumulative entries formed an assessed assignment of 2,000 words in length. The data amassing from those journals totalled around 100,000 words, and while not a part of the present project, necessarily informed the author's perspective in constructing it. The second stage included a five-point Likert scale survey completed anonymously and independently, approximately one month after the LLE had ended. By posing all but one closed questions, the survey captured teachers' responses to specific elements of the experience; while the single open-ended question offered the opportunity for greater disclosure. By implementing the survey at a delayed point in time, it uncovered what had remained salient in the minds/memories of teachers. The questionnaire included 14 items (see Appendix). Additional data consisted of the instructor's teaching materials and field notes relating to both the weekly SLD lectures and to the LLE components of these lectures.

\section{Analysis}

Descriptive statistics were used to analyze the closed survey question, while the single open-ended question was analysed thematically. The instructor-lecturer's notes and materials were crosschecked with teachers' weekly journals, and offered a triangulation of perceptions.

\section{Results and discussion}


Items 1-8 led teachers to evaluate the LLE in eight categories: results are presented in Table 1 below, with data presented as percentages of the whole.

Table 1. Items 1-8 and teacher responses.*

\begin{tabular}{|c|c|c|c|c|c|c|}
\hline & & $\begin{array}{l}1 \\
\text { no } \\
\text { value }\end{array}$ & $\begin{array}{l}2 \\
\text { little } \\
\text { value }\end{array}$ & $\begin{array}{l}3 \\
\text { some } \\
\text { value }\end{array}$ & $\begin{array}{l}4 \\
\text { consid. } \\
\text { value }\end{array}$ & $\begin{array}{l}5 \\
\text { high } \\
\text { value }\end{array}$ \\
\hline & L1 AND L2 & & & & & \\
\hline 1 & Language structure & $1.7 \%$ & $1.7 \%$ & $22 \%$ & $35.6 \%$ & $39 \%$ \\
\hline 2 & Difference between languages & 1.7 & 0 & 16.7 & 35 & 46.7 \\
\hline 3 & Relationship between language \& culture & 1.7 & 0 & 18.3 & 28.3 & 51.7 \\
\hline 4 & $\begin{array}{l}\text { Cultural differences } \\
\text { L2 LEARNING }\end{array}$ & 0 & 1.7 & 11.7 & 36.7 & 50 \\
\hline 5 & Language learning & 1.7 & 1.7 & 8.5 & 39 & 49.2 \\
\hline 6 & Individual learner variables & 0 & 3.4 & 5 & 41.7 & 50 \\
\hline 7 & Learners' affective states & 0 & 3.4 & 6.8 & 44.1 & 45.8 \\
\hline 8 & Learning styles/strategies & 0 & 1.7 & 6.8 & 44.1 & 47.5 \\
\hline
\end{tabular}

* $1.7 \%$ of 60 respondents represents one person; and 3.4\%, two persons

The teachers responded very positively to all eight closed survey questions, perceiving that they had developed an enhanced awareness of aspects of language, culture, and learning. By collapsing categories of 4 and 5, responses are seen to lie within the 75-92\% positive range. As a brief summative snapshot, then, the results are unequivocal; and indeed, confirm the positive responses exhibited by teachers in earlier qualitative studies of the LLE (e.g. Suarez, 2002; Angelova, 2005; de Courcy, 2005).

Teachers gave a similarly positive rating to Item 9: "Evaluating teaching strategies was not an aim of the LLE. However, to what extent were these of value to you as an ESL teacher?"; this time of $84.4 \%$.

Table 2. Item 9 and teacher responses.

\begin{tabular}{|c|c|c|c|c|c|c|}
\hline & & $\begin{array}{l}1 \\
\text { no } \\
\text { value }\end{array}$ & $\begin{array}{l}2 \\
\text { little } \\
\text { value }\end{array}$ & $\begin{array}{l}3 \\
\text { some } \\
\text { value }\end{array}$ & $\begin{array}{l}4 \\
\text { consid. } \\
\text { value }\end{array}$ & $\begin{array}{l}5 \\
\text { high } \\
\text { value }\end{array}$ \\
\hline 9 & The value of teaching strategies & 3.4 & 1.7 & 10.2 & 35.6 & 49.2 \\
\hline
\end{tabular}

Item 10 pushed teachers to an even simpler evaluative choice: "On balance, do you think that the subject of SLD in this course would best be served by (i) maintaining or (ii) discarding the Thai language learning component?" Retention of the LLE was supported by $96.6 \%$ of teachers - that is, by all but two. The fact that support was nearly unanimous indicates no significant difference between the reported views of the $89 \%$ of monolingual teachers and $11 \%$ of bilingual teachers in the project.

It should be noted, of course, that teachers' responses do not demonstrate that learning did actually occur in these respects: what we have are simply teachers' own beliefs about what they had learnt (items 1-9), and their views on the retention of the LLE (item 10).

The final two closed-response questions concerned the duration of the program, which on each occasion had occupied three of the 26 face-to-face teaching hours allocated to the SLD subject. Teachers were asked whether that subject would increase in value if the LLE occupied more (Q 12) or less (Q 13) time in the program. Forty percent of teachers agreed with the LLE occupying more time within the SLD subject; $29 \%$ disagreed; and 31\% were neutral. Sixty-five percent of teachers disagreed with the program occupying less time; 
$14 \%$ agreed; and $21 \%$ were neutral. It appears that teachers were inclined towards the program being retained in its current time-frame, with a minority favouring expansion and a majority opposing reduction.

The single open-response question was Item 11, which followed up Item 10 (retaining or discarding the LLE) by asking: "Can you give a reason?". This item was devised to elicit a relatively short response which might lead teachers to identify or summarise key outcomes which were salient to them one month after the LLE had ended. Fifty of the 60 participating teachers responded to this question, typically with a short paragraph, but sometimes with more or less comment. These responses were searched for common themes, coded, and ranked in order of frequency as set out below.

1. Experiential learning

2. Awareness of affect in learning

3. Connection between theory and practice

4. Awareness of language and culture

5. Teaching methodology

6. Design features of the LLE itself.

\section{Experiential learning}

The value of first hand experience was the strongest theme, emerging in some 19 responses. Many teachers commented on enhanced understanding of the challenges faced by ESL learners; and a number stressed that insights gained from this experience were qualitatively different from academic learning.

It is not possible to go through this experience by listening to people talk about it or by reading about it in books.

It was useful... 'to walk in somebody else's shoes'.

I feel that many teachers in our system have only a monolinguistic background and need to experience the language component, to give a brief encounter of the difficulties it presents and relate this to the children we teach.

I think it is crucial for all teachers/ ESL teachers who teach NESB students to experience learning another language from scratch, particularly if they have never learnt another L2 before....

Instructor-lecturer commentary From my dual perspective as instructor and lecturer, I also note that the tenor of classroom discourse changed both during and after LLE sessions, as experienced teachers became novice students again; and rather unexpectedly, the lecturer appeared to have gained credibility in teachers' eyes from having been viewed in a 'real' teaching role, as distinct from that of 'academic'. Moreover, I felt that an enhanced solidarity with teachers had developed through this shared experience, which sometimes displayed itself through mutual teasing about our various performances as 'teacher' and 'student'.

As for my own development as teacher-educator, I also gained from the experience of teaching a language which was not my native tongue. I was reminded, for example, of the constraints sometimes felt by NNS teachers if 'put on the spot' by requests to translate or explain unfamiliar L2 lexis or grammar. At the same time, because I shared an L1 of English with my 'students', I had the capacity, utilised in the last five minutes of each session, to explain points of the L2 through L1; and additionally, found that I could predict quite accurately what Englishspeaking learners might find difficult in learning Thai. My enhanced awareness of a NNS perspective fed back not only into the SLD subject, but into other, more practically-oriented parts of the program, where it helped me to illustrate why English is often taught so differently by NS and NNS teachers and in ESL and EFL contexts. 


\section{Awareness of affect in learning}

The second most prominent theme (15 responses) related to affect in learning:

I have learnt language before... but I'd forgotten what it really feels like.... [emphases in original].

... made the teacher realise and experience the pain and joys that our children go through in coping in a new country and new classroom.... I personally have found that I have become more compassionate and patient with my students.

It has made me much more aware of how difficult it is for SLL students to listen to English all day.

I experienced first hand the situation, the anxiety, frustration, small rewards, development of confidence....

Instructor-lecturer commentary The Thai language was deliberately chosen for its exoticism (see Bailey, Curtis \& Nunan, 2001, p. 99), rather than, say, French, which was also available to the instructor. There were very few points of connection which could be made between Thai and English, or with the languages previously learnt by most teachers. Teachers thus became absolute beginners; and when faced with my exclusive use of the L2, experienced a marked loss of power. Perhaps this loss of power was felt particularly strongly by K-12 teachers, whose role would generally be distinguished from that of teachers of adults by more explicit management of children's behaviour, as well as an official 'duty of care'. While I can say that all students appeared to be positively disposed to the LLE, there was a notable range of affect - like Bailey (1983), I observed moments of pleasure, anxiety, and occasionally competitiveness in these 'lessons'. The short debriefs in English had been not only of intellectual value, but salutary in affective impact. Each week, the moment when I switched from Thai to English was accompanied by teachers' sighs, sometimes groans, sometimes laughter; followed by animated discussion.

Once again, I benefitted as the instructor from witnessing the strength and range of teachers' responses to formal L2 learning. There was an advantage too in that these were also experienced professionals who could articulate informed responses to one another and to me. As instructor, my own affective response was principally one of excitement. This was partly due to the intense impact I could see that the LLE was having on teachers, but also because to teach Thai rather than English challenged me to communicate successfully within a non-expert command of L2 - again, a situation often experienced by EFL and other foreign language teachers worldwide. Moreover, there was pressure for me to 'perform' well. For unless the teaching itself was of good quality, teachers would understandably turn their attention to methodology, which was not what I wanted, either for academic or - to be honest - personal reasons.

Principally, then, teachers valued the LLE in two respects: its experiential nature, and its affective impact. In both respects, the LLE may be said to have contributed to language learning awareness: "the understanding of and empathy with the challenges faced by learners of an additional language' (E. Ellis, 2012, p. 15). Such awareness is not impossible to develop by other means, of course, but perhaps rather more difficult. Indeed there must be few domains of teaching where it is not an expectation that the teacher has already trodden a similar intellectual and experiential pathway to that taken by her/his students - which in this case, means learning a second/additional language.

\section{Connection between theory and practice}

It is interesting to note that this theme was less frequently referenced, even though it was a central aim of the LLE. In one sense, it seems that teachers had already satisfied the requirement to connect 
theory and practice by means of their written assignment as described earlier ('Stage 1'). And at the second stage, one month later, it was not the intellectual connection which stood out in teachers' minds: it was how they felt about undertaking this experience. Seven teachers, however, did note the ways in which the LLE had strengthened connections between theory and practice.

[The LLE] scaffolds the complex research and gives framework for thoughts. The SLD field is very broad, and this component provides a valuable focus.

Initially I couldn't see the value of the Thai component, but when I started writing the assignment, I realised that I could relate my learning to the readings and thus gained a better understanding of them.

[it was valuable to draw links with:] culture (host) resistance to learner; learner resistance to host language; acculturation; high/low enclosure... and to assist in drawing links with research which would otherwise appear unrelated and unused.

Instructor-lecturer commentary Benefits of the LLE in this respect unexpectedly accrued to me as subject lecturer. In theoretical sessions, I was able to refer back and forth from the literature to teachers' recent language learning.

For example. In Module 1, L1 and L2, drawing upon the work of Odlin (1989), I was able to exemplify discussion of contrastive/error analysis, language transfer, and crosscultural pragmatics with reference to Thai and English. The use of an Asian language both structurally and culturally distant from English was of particular value because it afforded clear comparisons. I could point, for example, to the ways in which lexical tones distinguish meaning in Thai and other languages; to Thai's different morphology, such as the use of a simple one-phrase tag question compared to the variety of forms in English; and to particular conventions, verbal and non-verbal, for expressing politeness across languages/cultures. My field notes highlight that even seemingly small cultural differences allowed for reappraisal of what is customary. In Thai, for example, teachers learned that first names are the point of entry in telephone listings; and that to use 'thank you' with the same frequency as is expected in English would denote not politeness but insincerity. More broadly, I could point to changing views in SLA on the role of the first language, and asked students to recall their LLE when responding, for example, to Vivian Cook's view that all L2 classroom activities are 'cross-lingual', and that:

the difference among activities is whether the L1 is visible or invisible, not whether it is present or altogether absent (1999, p. 202).

In Module 2, The Learning Environment, discussions of behaviourist, nativist, and social constructivist theory could be related directly to teachers' own experience of learning Thai. How much did an 'input-rich' environment contribute to their learning? What kind of scaffolding did they experience, and how effective was it? How about the role of repetition: is it to be discarded along with behaviourist theory; or perhaps not? What is the place of silence, or delayed speaking? Leading questions such as those provided by Lightbown and Spada (1999; 2006, p. xiv) were addressed by drawing upon teachers' recent experiences as L2 students in tandem with their current roles as L2 teachers.

Module 3 was concerned with The Learner. There is an array of individual variables (Brown, 2000), which is sometimes bewildering for novices to the literature. Teachers were able to test some of these research findings against their own and their colleagues' language learning experiences. As adult, highly literate learners, some teachers were not comfortable with my oral approach to Thai, with many having attempted but not quite succeeded in writing down all new Thai words. It was important to bring out such points when I lectured on the different characteristics of students who were or were not already literate in L1, for example; upon individual learner differences in tolerance towards ambiguity; upon levels and types of student motivation/investment. 
Parts of Module 4, Bilingualism, I could also relate to the methodology employed in the LLE. As noted earlier, in the final five minutes of each lesson I had reverted from exclusively Thai to English. The contrast proved to be illuminating, particularly for a number of teachers who had hitherto striven for 'English-only' in their own ESL classes and had opposed their students' use of bilingual dictionaries. As well highlighting pedagogy in this module, I was able to explore the psychology of L2 learning, for example by linking teachers' highly personal LLE to the classic 'linguistic interdependence' model (Cummins, 1991): "Did you feel that Thai and English were in separate pots, or one pot?"; and to theories of identity (Kramsch, 2000): "Did you feel that different/new parts of the self were presented when you, or your instructor, spoke Thai?".

\section{Awareness of language and culture}

All the teachers in this project dealt on a daily basis with students from a wide range of languages and cultures; immigration to Australia for many years now has principally been from S E Asia, East Asia, and the Middle East. But of the 60 participating teachers, only three were bilingual in an Asian language (two in Mandarin, and one in Hindi). As noted at the start of this paper, as well as observing teacher resistance to the SLA subject itself, I held concerns about the sometimes ethnocentric views expressed by teachers during class discussions and in assigned work. The survey results show that teachers believed the LLE had contributed to changing their awareness of language and culture (Table 1); and that in this respect, the choice of an Asian language distant from English was of particular value.

Especially important and valuable for anyone who has not lived in a country where they are the 'non-native' speaker. [punctuation as in the original].

The Thai language was also best as it is culturally very different - as English is to most NESB [Non-English Speaking Background] students.

[the language selected]... not necessarily Thai, but certainly a language we are unlikely to know, ie not even something with our [Roman] alphabet.

\section{Teaching methodology}

As noted earlier, I attempted to dissuade teachers from analysing methodology in their assigned work, while knowing full well that my every move would be under scrutiny. Fortunately, the methodology itself was viewed favourably (84.8\%). In their open-ended responses, only a few teachers commented, yet did so in positive terms.

It also made me aware of the need to learn language for concrete situations, especially for beginners.

The teaching strategies used also helped me to think about how I teach, and how effective this is with the ESL children - this caused some changes in my program.

As an added extra, I also found myself checking on how I communicate with the parents of the ESL children who had poor English skills - attempting to make myself clearer and check that they were understanding me.

\section{Design features of the LLE itself}

While only a few teachers commented on this aspect, most were satisfied with the LLE as it was currently designed. Three teachers proposed the use of a different, more common community language for the LLE. One acknowledged that: 
... other community languages may be or more practical use [but] it would be hard perhaps to find such a language that was appropriate..., new arrivals' countries of origin changing as they do.

Three teachers referred to the situation as artificial:

The purpose was to do an assignment rather than to learn a language, so it is something of a 'false experience'.

And two teachers argued for maintaining the LLE, with 'no choice' regarding participation:

... I think the aspect of 'no choice' is an important one - our students certainly have no choice.

\section{Conclusion}

\section{Impact on subject-lecturer}

It was only as I taught the LLE as a component of the SLD subject that I observed some interesting and unanticipated outcomes. First, as noted earlier, teaching a foreign language such as Thai was a new experience, which required me to move from being an expert L1 (English) teacher to a non-expert FL (Thai) teacher. I spent a great deal of time preparing the six lessons, which were refined with each of the three cohorts of teachers, and as I did so, gained a better understanding of the different conditions and needs of NNS teachers of EFL. Unfortunately, Western TESOL teacher training programs are still said to show little evidence of addressing the quite distinctive needs of such teachers (Lo, 2005; Liyanage \& Bartlett, 2008).

A second unanticipated outcome was the changing roles which I took on both during and after the LLE. During the LLE sessions, as noted earlier, my role was more limited, more powerful, and often came with an enhanced sense of performance. Like the teachers in the LLE, I was reminded of the huge importance of the interpersonal in learning; and when I spoke in Thai, could feel what has been well described as the:

disparity between the "true" self as known by the language learner and the more limited self as can be presented at any given moment in the foreign language (Horwitz, Horwitz \& Cope, 1986, p. 128).

After the LLE sessions, there was often an enhanced sense of solidarity and collegiality. Even longer term, when I sometimes run into former graduate students, it is often memories of this LLE that are the first to be recalled, and usually in pleasurable ways.

Thirdly, the initial problem of the relatively inaccessible SLD literature was ameliorated by the LLE, because I could so readily, module by module, link theoretical concepts to what we had collectively experienced. All in all, if I put my performance anxiety aside, I can say that only positive outcomes emerged from my participation; and that these were all the more welcome for not having been anticipated to occur. If we look to the broader picture of research by language teacher-educators into their own practice, which is still said to be 'rare' (Wright, 2010, p. 287) or 'emerging' (Barkhuisen \& Borg, 2010, p. 237), it is hoped that the current project can make a contribution.

\section{Impact on participating teachers}

An unexpected finding of the present project was that bilingual participating teachers regarded the LLE no less highly than did their monolingual colleagues. I note that nearly all the bilingual teachers were of European language backgrounds: it could be that the exotic nature of the target language, Thai, represented a new experience of encountering a language which appeared to have few 'signposts'. Alternately, or additionally, it may have been the role reversal required of teachers to become students - and relatively powerless beginner 
students at that - which challenged all teachers, and which led to teachers' strong perceptions that they had grown to better understand language, learning and culture as a result of their LLE.

Based on this project, I propose two possible models that LLEs may take in teacher education programs: 'integrated' and 'parallel', In the integrated model, L2 learning is delivered as part of an existing TESOL subject. The advantages of integration appear to be threefold. The TESOL lecturer retains control of the program design and to some extent its delivery, which enhances the likelihood of ensuring quality; the class itself remains intact, which enables the exchange of shared experiences and fosters group cohesion; and organisationally, an integrated program is relatively straightforward to manage.

In the second, 'parallel' model, teachers attend an existing FL class, and reflect upon that experience as part of assigned coursework within their TESOL degree. This second model may be less effective in terms of the three advantages mentioned above. That is, the TESOL lecturer is likely to have little or no control over the design and delivery of the program; the TESOL class is now dispersed; and management of the program and assigned work is likely to be complex if teachers select different languages at different sites. However, the parallel model offers greater depth of L2 learning, with all the benefits that entails, as illustrated for example in Flowerdew (1998), or Suarez (2002).

To look more broadly at the TESOL profession: although equity, diversity and inclusivity are core values, there is to my knowledge no major English speaking country which has a requirement for ESL teacher bilinguality either in its TESOL standards or in admitting candidates to TESOL teacher training. The New Zealand standards, however, do include broad guidance that TESOL teachers 'should have experience in learning another language' (see Haddock, 1998). Based on my experience as a TESOL subject lecturer, LLE instructor, and researcher, it is my belief that all teachers entering the TESOL profession should study at least one foreign language to intermediate level; and that this additional language should preferably be one which is linguistically and culturally distant from the teacher's mother-tongue.

\section{References}

Anglelova, M. (2005). Using Bulgarian mini-lessons in an SLA course to improve the KAL of American ESL teachers. In N. Bartels (Ed.), Researching applied linguistics in language teacher education (pp. 27-42). Boston, MA: Kluwer.

Bailey, K. M. (1983). Competitiveness and anxiety in adult second language learning: Looking at and through the diary studies. In H. W. Seliger and M. H. Long (Eds.), Classroom-oriented research in Second Language Acquisition (pp. 67-102). Rowley, MA: Newbury House.

Bailey, K. M., Curtis, A., \& Nunan, D. (2001). Pursuing professional development: The self as a source. Boston, MA: Heinle \& Heinle.

Barkhuisen, G., \& Borg, S. (2010). Editorial: Researching language teacher education. Language Teaching Research, 14, 237-240.

Bartels, N. (2002). Professional preparation and action research: Only for language teachers? TESOL Quarterly, 36, 71-79.

Bigelow, M., \& Tedick, D. J. (2005). Combining foreign and second language teacher education: Rewards and challenges. In D. J. Tedick (Ed.), Second language teacher education: International perspectives (pp. 295-311). Mahwah, NJ: Erlbaum.

Borg, S. (2003). Teacher cognition in language teaching: A review of research on what language teachers think, know, believe, do. Language Teaching, 36, 81-109.

Brown, H. D. (2000). Principles of language learning and teaching, $4^{\text {th }}$ edn. New York: Longman. de Courcy, M. (2005). The effect of learning a new language on ESL teachers' beliefs about language pedagogy. Australian Language and Literacy Matters, 2, 7-13.

Cook, V. (1999). Going beyond the native speaker in language teaching. TESOL Quarterly, 33, 185-209. 
Cummins, J. (1991). Interdependence of first- and second-language proficiency in bilingual children. In E. Bialystok (Ed.), Language processing in bilingual children (pp. 7089). Cambridge: Cambridge University Press.

Ellis, E. M. (2004). Language background and professional competencies in teaching ESOL. English Australia, 21, 55-71.

Ellis, E. M. (2006). Language learning experience as a contributor to ESOL teacher cognition. TESL-EJ, 10. Retrieved from http://tesl-ej.org/ej37/a3.html.

Ellis, E. M. (2012). Language awareness and its relevance to TESOL. University of Sydney Papers in TESOL, 7, 1-23.

Ellis, R. (2010). Second language acquisition, teacher education and language pedagogy, Language Teaching, 43, 182-201.

Flowerdew, J. (1998). Language learning experience in L2 teacher education. TESOL Quarterly, 32, 529-536

Forman. R. (2010). Ten principles of bilingual pedagogy. In A. Mahboob (Ed.), The NNEST lens: Non native speakers in TESOL (pp. 54-86). Newcastle-Upon-Tyne: Cambridge Scholars.

Forman, R. (2012). Six functions of bilingual EFL teacher talk: Animating, translating, explaining, creating, prompting and dialoguing. RELC Journal, 43, 239-253.

Gibbons, P. (2003). Mediating language learning: Teacher interactions with ESL students in a content-based classroom. TESOL Quarterly, 37, 247-273.

Gorsuch, G. J., \& Beglar, D. (2004). Teaching second language acquisition courses: Views from new faculty. TESL-EJ, 8. Retrieved from http://tesl-ej.org/ej29/a2.html.

Haddock, D (1998). New Zealand TESOL professional characteristics and the indicators of competence. TESOLANZ Journal, 6, 89-99.

Horwitz, E. K., Horwitz, M., \& Cope, J. (1986). Foreign language classroom anxiety. Modern Language Journal, 70, 125-132.

Lightbown, P. M., \& Spada, N. (1999). How languages are learned, $2^{\text {nd }}$ edn. Oxford: Oxford University Press.

Lightbown, P. M., \& Spada, N. (2006). How languages are learned, $3^{\text {rd }}$ edn. Oxford: Oxford University Press.

Linguaphone Thai Language Course. (1995). London: Linguaphone Institute.

Liyanage, I., \& Bartlett, B. J. (2008). Contextually responsive transfer: Perceptions of NNES on an ESL/EFL teacher training programme. Teaching and Teacher Education, 24, $1827-1836$.

Lo, G. Y-H. (2005). Relevance of knowledge of second language acquisition. In N. Bartels (Ed.), Researching applied linguistics in language teacher education (pp. 135-158). Boston, MA: Kluwer.

MacDonald, M., Badger, R., \& White, G. (2001). Changing values: what use are theories of language learning and teaching?. Teaching and Teacher Education, 17, 949-963.

Odlin, T. (1989). Language transfer: Cross-linguistic influence in language learning. New York: Cambridge University Press.

Suarez, D. (2002). ESOL teacher candidates experience cultural otherness. TESOL Journal, $11,19-25$.

van Lier, L. (2004). The Ecology and semiotics of language learning: A sociocultural perspective. Norwell, MA: Kluwer.

Wallace, M. J. (1991). Training foreign language teachers: A reflective approach. Cambridge: Cambridge University Press.

Wright, T. (2010). Second language teacher education: Review of recent research on practice. Language Teaching 43, 259-296.

Wright, T. \& Bolitho, R. (1997). Towards awareness of English as a professional language. Language Awareness, 6, 162-170.

\section{Appendix}




\section{Questionnaire}

\section{Q. 1-8}

How valuable was this component in raising your awareness of the following? Select one rating. Key:

5 high value

4 considerable value

3 some value

2 a little value

1 no value

\begin{tabular}{lllllll} 
& \multicolumn{2}{l}{ high } & & & low \\
\hline & L1 AND L2 & & & & & \\
\hline 1 & language itself & 5 & 4 & 3 & 2 & 1 \\
\hline 2 & differences between languages & 5 & 4 & 3 & 2 & 1 \\
\hline 3 & relationship between language \& culture & 5 & 4 & 3 & 2 & 1 \\
\hline 4 & cultural differences & 5 & 4 & 3 & 2 & 1 \\
\hline & L2 LEARNING & & & & & \\
\hline 5 & language learning & 5 & 4 & 3 & 2 & 1 \\
\hline 6 & individual learner variables & 5 & 4 & 3 & 2 & 1 \\
\hline 7 & learners' affective states & 5 & 4 & 3 & 2 & 1 \\
\hline 8 & learning styles/strategies & 5 & 4 & 3 & 2 & 1 \\
\hline
\end{tabular}

\section{Q.9}

Evaluating teaching strategies was not an aim of the LLE. However, to what extent were these of value to you as an ESL teacher?

\begin{tabular}{lllllll} 
& & high & & low \\
\hline 9 & The value of teaching strategies & 5 & 4 & 3 & 2 & 1 \\
\hline
\end{tabular}

\section{Q. 10}

On balance, do you think that the subject of Second Language Development in this program would best be served by (a) maintaining, or (b) discarding the Thai LLE?

\section{Q. 11}

Can you give a reason?

\section{Q. 12-14}

If maintained, do you think that this SLD subject would increase in value if the LLE were amended in the ways listed below? Select one rating:

\begin{tabular}{|l|l|l|l|l|}
\hline $\begin{array}{l}\text { strongly } \\
\text { agree }\end{array}$ & agree & neutral & disagree & $\begin{array}{l}\text { strongly } \\
\text { disagree }\end{array}$ \\
\hline 5 & 4 & 3 & 2 & 1 \\
\hline
\end{tabular}

12. occupied more time in the program

13. occupied less time in the program

14. utilised a more common community language. 